\title{
An Empirical Study on Organizational Determinants of RFID Adoption in the Logistics Industry
}

\author{
Chieh-Yu Lin (I)
}

\begin{abstract}
Radio frequency identification technology (RFID) has been taken as an important application in logistics operations. However, scarce attention has been paid on empirically studying factors affecting the adoption of RFID in the logistics industry. The main purpose of this paper is to study organizational determinants of RFID adoption by logistics companies. A questionnaire survey on logistics companies in Taiwan was conducted to test proposed research hypotheses. Research findings reveal that organizational support for innovation, the quality of human capital, organizational knowledge accumulation, and company size are significantly positively associated with the adoption of RFID. According to research results, managerial implications and opportunities for future research are discussed as well.
\end{abstract}

Keywords: RFID, organizational determinants, technology adoption, logistics industry.

(I) Associate Professor, Department of International Business. Chang Jung Christian University 396, Sec. I, Chang Jung Rd., Kway Jen, Tainan, 71 I 01 , Taiwan

Tel: 886-6-2785I 23 ext 2154 Fax:886-6-2785662 E-Mail: jylin@mail.cjcu.edu.tw 


\section{Introduction}

Over the past decade, many logistics companies have acknowledged that their logistics operations are not responsive enough. If they are to operate more efficiently and responsively, they must adopt technologies that will manufacturers, warehouses, and retailers to communicate with each other more efficiently (Cohen, 2000). Among many logistics technologies, radio frequency identification technology (RFID) has been taken as an important application in logistics operations and supply chain management (Angeles, 2005; Smith, 2005; Srivastava, 2004). Federal Express, Dell, Proctor and Gamble, Wal-Mart, the US Department of Defense, and the European retailer Metro Group have begun to utilize RFID technology in their supply chain systems (RFID Journal, 2004).

RFID is one type of auto-identification technology that uses radio waves to identify individual physical objects, and has been used for in many applications including the manufacturing and distribution of physical goods. An RFID tag consists of two main components: an antenna and a chip containing an electronic product code. RFID can help item level identification, which is useful for easily and efficiently identifying each item within the entire supply chain (Davis and Luehlfing, 2004). Due to the application of radio frequency, we can interact with the product items without physical contact, and as a result, increase our handling efficiencies. In summary, RFID provides a tool for real-time data communication and can close the information gaps in the supply chain, especially in retailing and logistics; therefore RFID allows for better control of supply chain due to effective information sharing and real-time data communication (Angeles, 2005; Prater et al., 2005; Yao and Carlson, 1999).

Although RFID has garnered a great deal of research interest, most research has primarily focused on the specifics of the technology, or its impact on general supply chain issues, such as its general promise of cost and time savings (Angeles, 2005; Davis and Luehlefing, 2004; Donovan, 2003; Kärkkäinen, 2003; Kunii, 2003; Niemeyer and Pak, 2003; Smith, 2005; Srivastava, 2004). What has been missing is a discussion of the drivers or influencing factors that lead various industries to consider RFID (Prater et al., 2005). Some studies argued that the key factor for widespread usage of RFID is its cost (Donovan, 2003). However, it is still not clear whether organizational factors will affect the adoption of RFID.Therefore, the main purpose of this paper is to explore the organizational factors that will affect the willingness to adopt RFID for logistics companies.

The next section introduces the theoretical foundation of the organizational determinants of RFID adoption. The third section gives a description of the research methodology, while the fourth section focuses on the analysis of the results and the discussion of the findings. The final section gives conclusions, implications, and limitations.

\section{Organizational Determinants of RFID Adoption}

The application of RFID is still in its infancy (Davis and Luehlefing, 2004).As a result, the adoption of RFID can be taken as an innovative process for a logistics company. Therefore, this paper will utilize the concept of innovation to investigate the factors affecting the willingness to adopt RFID. Innovation is the use of new technical and administrative knowledge to offer a new product or service to customers. It includes any practices that are new to organizations, including equipments, products, services, processes, policies and projects (Kimberly and Evanisko, 198I). Among several factors influencing innovation, organizational factors are the most widely analyzed in research on innovation (Kimberly and Evanisko, 198I; Tornatzky and Fleischer, 1990). This paper will investigate the influence of organizational factors on adopting RFID.

Certain features of organizations themselves, including structures, climates, and cultures of organizations, will influence innovation (Kimberly and Evanisko, 198I; Russell and Hoag, 2004; Tornatzky and Fleischer, 1990). The management skills, organizational encouragement for innovation, and support of innovation resources would help the improvement of organizational innovation (Amabile, 1988). The support and encouragement of top management is considered an essential factor for the development of innovation strategies because the resources required for the implementation of new technologies will be more easily available if the major person responsible for these resources supports the plans. Moreover, many initiatives of adopting new technologies require the collaboration and coordination of different departments and divisions and this is easier to manage when such initiatives are endorsed from the top. Therefore, we would expect that support for innovation might influence the adoption of RFID technology. The following hypothesis is consequently proposed:

Hypothesis $\mathrm{HI}$ The more the support for innovation, the more the willingness that logistics companies will have to adopt RFID technology.

Informal linkages and communication among employees, the quality of human resources, top management's leadership behavior, and the amount of internal slack resources would significantly influence the adoption of technological innovation (Tornatzky and Fleischer, 1990). Technologies can be viewed as one kind of knowledge (Grant, 1996).) An organization will have higher innovative capability when knowledge can be distributed more easily within the organization (Tsai and Ghoshal, 1998). Higher quality of human capital such as employees with better education or training is helpful to distribute technological 
knowledge in an organization. The higher the percentage of employees trained in learning innovative knowledge is, the higher the development of the organization' innovative approaches will be. Therefore, we would expect that the quality of human capital might influence the adoption of RFID technology. The following hypothesis is consequently proposed:

Hypothesis $\mathrm{H} 2$ The higher the quality of human capital, the more the willingness that logistics companies will have to adopt RFID technology.

How the technology fits in with the operational knowledge that a firm already possesses is an important factor influencing innovation (Chau and Tam, 1997; Tornatzky and Fleischer, 1990). Innovation usually follows a technological paradigm (Teece, 1996). The organizational accumulation of related knowledge will influence the innovation in technologies. An organization with rich experiences in the application or adoption of related technologies will have higher ability in technological innovation (Grant, 1996; Simonin, 1999). In addition, companies with a higher level of innovation capacity innovate more frequently in a radical way (Clark and Fujimoto, 1989). The companies that have an adequately integrated innovation capacity will recognize its express purpose to solve problems, such as the adoption of RFID technology. Thereby, the most advanced and most competence-modifying technologies will emerge as a result of accumulated R\&D activities (Rogers, 2003). Therefore, we would expect that organizational accumulation of related knowledge might influence the adoption of RFID technology. The following hypothesis is consequently proposed:

Hypothesis H3 The more the organizational accumulation of related knowledge, the more the willingness that logistics companies will have to adopt RFID technology.

Company size, usually measured by the number of employees, is an important variable in technological innovation (Spencer, 2003). It is one of the structural variables that most seems to influence the implementation of innovative practices (Zhu et al., 2008). Large companies have more resources available to devote to technological innovation. Therefore, we would expect that company size might influence the adoption of RFID technology.The following hypothesis is consequently proposed:

Hypothesis H4 The larger the company size, the more the willingness that logistics companies will have to adopt RFID technology.

\section{Methodology}

\section{Data Collection and Sample Description}

To test above hypotheses, data were collected by means of mailing questionnaires to logistics companies in Taiwan. This region is interesting because Taiwan is one of the important sources of electronic hardware products in the world, and its effective logistics operations is one of the key success factors of Taiwan (Shan and Marlow, 2005). Many logistics companies in Taiwan have adopted new technologies to improve their logistics service performance. The sample frame was drawn from members of a logistics council in Taiwan. Five hundred questionnaires were mailed to the sampled companies. In total, I 5 I completed questionnaires were returned. Of these respondents, 9 uncompleted or unconfident questionnaires were excluded. The overall response rate is $\mathbf{2 8 . 4}$ percent. The basic information of these companies is shown in Table $I$.

\begin{tabular}{|c|c|c|c|}
\hline & Category & Number & Percentage (\%) \\
\hline \multirow{4}{*}{$\begin{array}{c}\text { Company history } \\
\text { (Years) }\end{array}$} & $0 \sim 5$ & 38 & 26.8 \\
\hline & $6-10$ & 35 & 24.6 \\
\hline & ||$-20$ & 41 & 28.9 \\
\hline & Above 20 & 28 & 19.7 \\
\hline \multirow{5}{*}{ Number of employee } & Below 50 & 31 & 21.8 \\
\hline & $51-100$ & 32 & 22.5 \\
\hline & $|0|-300$ & 30 & 21.2 \\
\hline & $301-500$ & 27 & 19.0 \\
\hline & Above 501 & 22 & 15.5 \\
\hline \multirow{2}{*}{ Bar Code experience } & Yes & $|2|$ & 85.2 \\
\hline & No & 21 & 14.8 \\
\hline \multirow{3}{*}{ Adoption of RFID } & Yes & 25 & 17.6 \\
\hline & No but Interested & 86 & 60.6 \\
\hline & No and Uninterested & 31 & 21.8 \\
\hline
\end{tabular}

Table I - Basic Information of the Sample 
Most logistics companies in Taiwan are small and medium size enterprises. Because RFID has been seen as a technology to replace bar code, the experience of using bar code was also studied. Most (about 85 percents) of logistics companies in Taiwan have the experience of using bar code in their logistics service processes.According to the survey results, it can be found that about sixty percent of logistics companies are interested in RFID, but only about 17 percents of them have the experience of adopting RFID.

\section{Measures}

The adoption of RFID is measured by asking respondents' willingness to adopt RFID. Organizational support for innovation is measured according to the degrees that companies' resource supports and leaders' attitudes (Amabile, 1988; Tornatzky and Fleischer, 1990). Quality of human capital is measured according to employees' information skills and innovation capabilities (Tornatzky and Fleischer, 1990). Organizational accumulation of related knowledge is measured according to the degrees of fitness of related technologies a firm that possessed (Chau and Tam, 1997; Grant, 1996; Simonin, 1999). Each item is measured using the 5-point Likert scales anchored by 'strongly disagree' and 'strongly agree'. The measured scales were submitted to factor analysis with varimax rotation. Factors with eigenvalues greater than 1.0 are summarized in Table 2 . The company size is measured by the number of employees (Spencer, 2003).

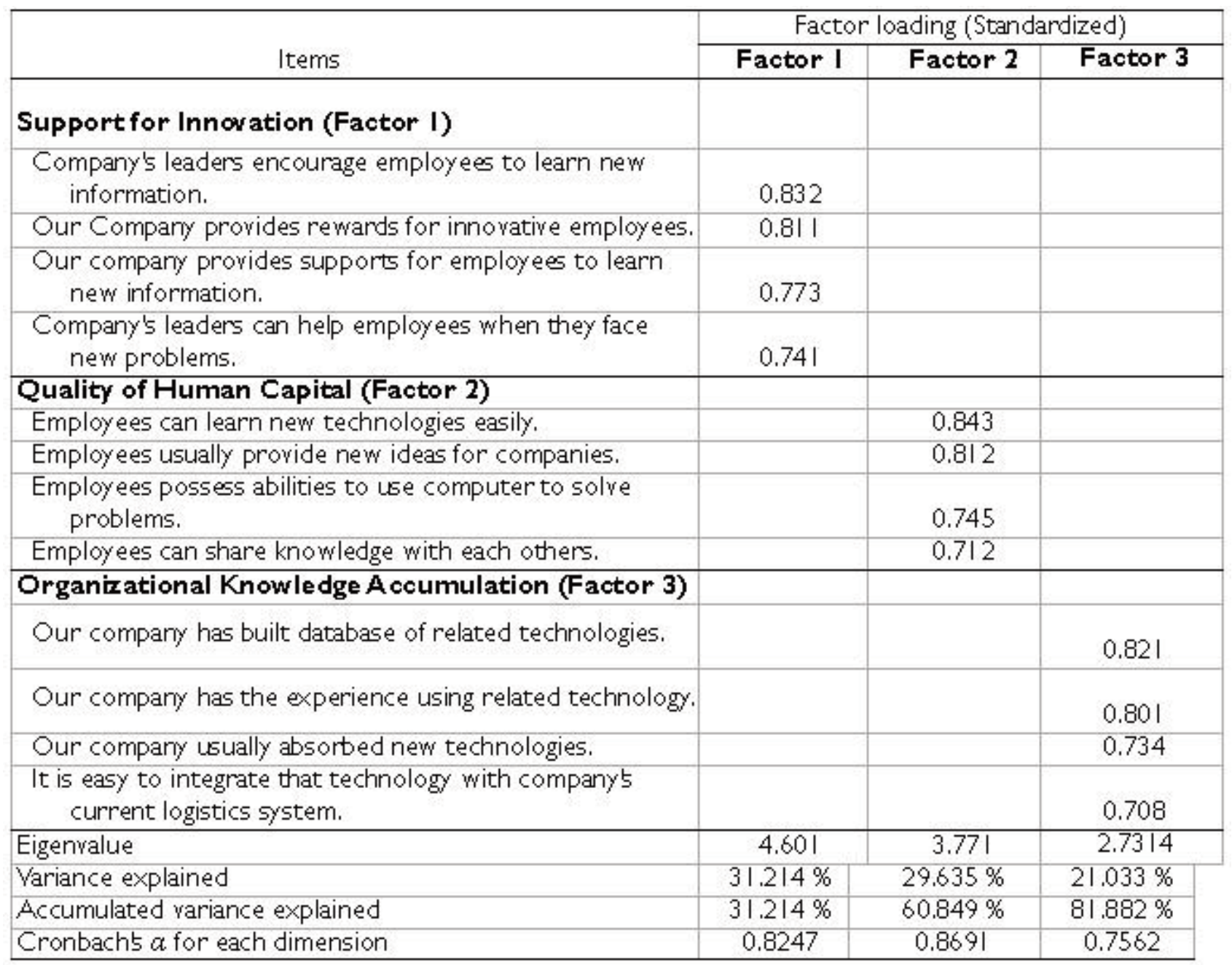

Table 2 - Result of Factor Analysis for Organizational Factors 
The reliability analysis is also conducted in the current study. The overall reliability is 0.8527 . As the smallest value of Cronbach's alpha for this study is 0.7562 , the sampling results are reliable (Nunnally, 1978). Table 3 shows the correlations among the organizational factors and the willingness to adopt
RFID technology. The correlation matrix gives us initial evidences of our hypotheses that proposed organizational factors are associated positively with the adoption of RFID technology. Moreover, the four organizational factors are not highly correlated.

\begin{tabular}{|l|l|l|l|l|l|l|l|}
\hline Variables & Means & Std. & $\mathbf{l}$ & $\mathbf{2}$ & $\mathbf{3}$ & $\mathbf{4}$ & $\mathbf{5}$ \\
\hline 1. Support for innovation & 4.12 & 0.91 & 1.0 & & & & \\
\hline 2. Quality of human capital & 3.91 & 0.93 & 0.28 & 1.0 & & & \\
\hline 3. Organizational knowledge accumulation & 3.37 & 0.84 & 0.17 & 0.24 & 1.0 & & \\
\hline 4. Compary size & 256.86 & 50.17 & 0.09 & 0.13 & 0.21 & 1.0 & \\
\hline 5. RFID adoption & 3.27 & 1.04 & $0.64^{* *}$ & $0.59^{* *}$ & $0.49^{*}$ & $0.41^{*}$ & 1.0 \\
\hline
\end{tabular}

Table 3 - Result of Correlation Analysis

\section{Results and Discussions}

To find the influences of organizational factors on the adoption of RFID, the method of multiple regression analysis was used in this study. Support for innovation, quality of human capital, organizational knowledge accumulation and company size are taken as independent variables and the willingness to adopt RFID is taken as the dependent variable. Moreover, as firm history (Spencer, 2003) and past experiences of similar technologies (Grant, 1996; Simonin, 1999) might influences the adoption of technological innovation, company history and bar code experience are taken as the control variables in the regression analysis. In the present regression model, the regression assumptions of homoescedasticity, linearity, normality, independence of residuals, and the absence of multicollinearity are all satisfied. The standardized results of regression analysis are shown in Table 4. We can find that the proposed organizational factors have positive influences on the adoption of RFID technology. Support for innovation, quality of human capital, organizational knowledge accumulation and company size all exhibit significantly positive influences on the willingness to adopt RFID technology for logistics companies in Taiwan. This means that the hypotheses, $\mathrm{HI}, \mathrm{H} 2, \mathrm{H} 3$, and $\mathrm{H} 4$ are supported.

\begin{tabular}{|c|c|c|c|c|}
\hline \multicolumn{5}{|c|}{ Dependent variables:Adoption of RFID } \\
\hline \multirow[b]{2}{*}{ Predictors } & \multicolumn{2}{|c|}{ Model I } & \multicolumn{2}{|c|}{ Model 2} \\
\hline & Coefficient $\beta$ & $t$ & Coefficient $\beta$ & $t$ \\
\hline \multicolumn{5}{|l|}{ Control variables } \\
\hline Company history & 0.008 & 0.498 & 0.003 & 0.501 \\
\hline Bar code experience & 0.047 & $1.639^{+}$ & 0.042 & $1.620^{+}$ \\
\hline \multicolumn{5}{|l|}{ Independent variables } \\
\hline Support for innovation & & & 0.213 & $5.847^{* *}$ \\
\hline Quality of human capital & & & 0.200 & $\left.5.03\right|^{* *}$ \\
\hline Organizational knowledge accumulation & & & 0.189 & $4.738^{* *}$ \\
\hline Company size & & & 0.182 & $4.017^{* * *}$ \\
\hline $\mathrm{R}^{2}$ & \multicolumn{2}{|c|}{0.089} & \multicolumn{2}{|c|}{0.516} \\
\hline $\operatorname{adj} R^{2}$ & \multicolumn{2}{|c|}{0.071} & \multicolumn{2}{|c|}{0.479} \\
\hline$F$ & \multicolumn{2}{|c|}{1.001} & \multicolumn{2}{|c|}{$6.913^{\text {k* }}$} \\
\hline
\end{tabular}

Table 4 - Standardized Regression Results for RFID Adoption 
More accumulation of RFID related knowledge can make logistics companies have more abilities to adopt RFID technology. Actually, the positive relationship between the experience of using bar code and the willingness to adopt RFID technology also reveals the positive influences of organizational accumulation of related technologies. Organizational support for innovation can give employees motivation and support to adopt new logistics technologies, such as RFID technology. High quality of human capital means that employees are capable of learn and use innovative logistics technology like RFID technology. The significant positive association between company size and RFID adoption implies that logistics companies with a larger scale may have more willingness to adopt RFID because they may own more resources for innovation.

\section{Conclusions}

As logistics companies must pay more and more attention to innovation in logistics technologies to provide better services for their customers in order to survive in the highly competitive times, recently, they utilize many innovative logistics technologies to reinforce their competitive advantages and to satisfy their customers' diversified needs. RFID technology is one of the most innovative logistics technologies. This paper studies the influences of organizational factors on the adoption of RFID for logistics companies in Taiwan. In addition to the exploration of determinants of adopting RFID technology, this paper also studies the development of RFID adoption in the logistics industry in Taiwan. We can find that only a few of logistics companies in Taiwan had the experience of adopting RFID technology though many of them are very interested in RFID technology. Based on the research results, we can logistics companies can also increase their abilities to adopt RFID by accumulating more related technologies, by encouraging or supporting their employees to learn new technology and by training and educating their employees to become knowledge workers.

There are some limitations to our research. Because we used the questionnaire survey, it is possible that the results of this study might suffer from the respondent bias. As we know, logistics companies cover a wide range of service types. In this study, we did not take the influences of service types of logistics companies on the adoption of RFID technology. There might be different effects of organizational factors on the adoption of RFID technology for different logistics service types. It is worthwhile to make a further study on the moderating effect of logistics service types on the adoption of RFID technology. Moreover, other possible influential factors on the adoption of RFID technology will also be taken into considerations in a further study. In addition, this paper only studies the influences of organizational factors on the adoption of RFID technology in
Taiwan's logistics industry. The current study may be limited in its generalizability. While there are differences between Taiwan and other countries in political structures, cultural background, historical perspective, social value, and so on, logistics companies in different countries may have different views on the influences of these organizational factors on the adoption of RFID technology. It will be worthwhile to advance a cross-national comparative study on the adoption of RFID technology among logistics industries in Taiwan and in other countries.

\section{References}

AMABILE,T. M. (1988). A model of creativity and innovation in organization. In B. M. Staw and L. L. Cummings (Eds.), Research in Organizational Behavior, Vol. 10, pp. 123-167, Chicago: Aldine Publishing Company.

ANGELES, R. (2005). RFID technologies: supply-chain applications and implementation issues, Information System Management, 22(I), 5I-65.

CHAU, P.Y. K., \& Tam, K.Y. (1997). Factors affecting the adoption of open systems: an exploratory study. MIS Quarterly, 2I(I), I-24.

CLARK, K. B., \& Fujimoto, T. (1989). Reducing the time to market: The case of the world auto industry. Design Management Journal, I (I), 49-57.

COHEN, S. L. (2000). The supermarket in 20I0, IIE Solutions, 32(4), 38-4I.

DAVIS, H. E., \& Luehlfing, M. S. (2004). Radio frequency identification: the wave of the future, Journal of Accountancy, 198(5), 4349.

DONOVAN, J. (2003). RF identification tags: show me the money, Electronic Engineering Times, May 12, p.4I.

GRANT, R. M. (1996). Prospering in dynamically-competitive environments: organizational capability as knowledge integration. Organization Science, 7(4), 375-387.

KÄRKKÄINEN, M. (2003). Increasing efficiency in the supply chain for short shelf life goods using RFID tagging, International Journal of Retail \& Distribution Management, 3I(10), 529-536.

KIMBERLY,J. R., \& Evanisko, M.J. (I98I). Organizational innovation: the influence of individual, organizational, and contextual factors on hospital adoption of technological and administrative innovations. Academy of Management Journal, 24(4), 689-7I3. 
KUNII, I. M. (2003). Radio ID tags so cheap they'll be everywhere, Business Week, October 20, p. 147.

NIEMEYER,A., \& Pak, M. H. (2003). Smart tags for your supply chain, The McKinsey Quarterly, No.4.

NUNNALLY, J. C. (1978). Psychometric theory. New York, NY: McGraw-Hill,.

PRATER, E., Frazier, G.V., \& Reyes, P. M. (2005). Future impacts of RFID on e-supply chains in grocery retailing, Supply Chain Management:An International Journal, I0(2), I34-I42.

RFID Journal (2004). Mandate for change, RFID Journal, January.

ROGERS, E. M. (2003). Diffusion of innovations, 5th ed. New York, NY: Free Press.

RUSSELL, D. M., \& Hoag, A. M. (2004). People and information technology in the supply chain: social and organizational influences on adoption. International Journal of Physical Distribution \& Logistics Management, 34(I/2), I02-1 22.

SHAN, K. C., \& Marlow, P. B. (2005). Logistics capability and performance in Taiwan's major manufacturing firms, Transportation Research Part E, 4I, 217-234.

SIMONIN, B. L. (1999). Transfer of marketing know-how in international strategic alliances: an empirical investigation of the role and antecedents of knowledge ambiguity, Journal of International Business Studies, 30(3), 463-490.

SMITH, A. D. (2005). Exploring radio frequency identification technology and its impact on business systems, Information Management \& Computer Security, I3(I), 16-28.

SPENCER, J.W. (2003). Firms' knowledge-sharing strategies in the global innovation system: Empirical evidence from the flat panel display industry. Strategic Management Journal, 24(3), 217 233.

SRIVASTAVA, B. (2004). Radio frequency ID technology: the next revolution in SCM, Business Horizons, 47(6), 60-68.

TEECE, D. J. (1996). Firm organization, industrial structure, and technological innovation. Journal of Economic Behavior and Organization, 3 I (2), I93-224.
TSAI,W., \& Ghoshal S. ( 1998). Social capital and value creation: the role of intra-firm networks. Academy of Management Journal, $4 I(4), 464-476$.

TORNATZKY, L. G., \& Fleischer, M. (1990). The process of technological innovation. Lexington, MA: Lexington Books, Lexington.

YAO,A. C., \& Carlson, J. G. (1999). The impact of real-time data communication on inventory management, International Journal of Production Economics, 59, 213-219.

ZHU, Q., Sarkis, J., Lai, K-H., \& Geng, Y. (2008). The role of organizational size in the adoption of green supply chain management practices in China. Corporate Social Responsibility and Environmental Management, I5(6), 322-337.

\section{About the Author}

Dr. Chieh-Yu Lin got his Ph.D. degree in National Cheng Kung University in Taiwan. He is now the Associate Professor at Department of International Business in Chang Jung Christian University. His research interests include management of technology, supply chain management, logistics management, and electronic business. 